\title{
Circadian variation in witnessed out of hospital cardiac arrest
}

\author{
L H Soo, D Gray, T Young, J R Hampton
}

\begin{abstract}
Objectives-To examine the effect on circadian variation of out of hospital cardiac arrest according to the underlying aetiology and presenting rhythm of arrest, and to explore strategies that might help to improve survival outcome using circadian variation.

Design-Population based retrospective study.

Setting-County of Nottinghamshire with a total population of 993914 and an area of $2183 \mathrm{~km}^{2}$

Subjects-Between 1 January 1991 and 3 December 1994, all witnessed cardiac arrests attended by the Nottinghamshire Ambulance Service, of which 1196 patients had a cardiac cause for their arrest (ICD, 9th revision, codes 390-414 and 420-429) and 339 had a non-cardiac cause.

Results-The circadian variation of the cardiac cases was not significantly different from that of non-cardiac cases $(p=0.587)$, even when adjusted for age, sex, or presenting rhythm of arrest. For cardiac cases, the circadian variation of those who presented with ventricular fibrillation was significantly different from those presenting with a rhythm other than ventricular fibrillation $(p=0.005)$, but was similar to the circadian variation of bystander cardiopulmonary resuscitation $(p=0.306)$ and survivors $(p=0.542)$. Ambulance response time was also found to have a circadian variation.

Conclusions-There is a common circadian variation of out of hospital cardiac arrest, irrespective of underlying aetiology, where the presenting rhythm is other than ventricular fibrillation. This is different from the circadian variation of cases of cardiac aetiology presenting with ventricular fibrillation. The circadian variation of ventricular fibrillation, and consequently survival, may be affected by the availability of bystander cardiopulmonary resuscitation and the speed of ambulance response.

(Heart 2000;84:370-376)
\end{abstract}

Keywords: out of hospital; cardiac arrest; circadian variation

\footnotetext{
Department of Cardiovascular Medicine, University

Hospital, Queens Medical Centre, University Hospital, Nottingham NG7 2UH, UK

L H Soo

D Gray

J R Hampton
}

Health Economics Research Group, Brunel University, Uxbridge, Middlesex, UK

T Young

Correspondence to: Dr Soo lin.soo@akgateway.net

Accepted 4 July 2000
A wide range of cardiovascular disease has been found to have circadian patterns, but the reason for this remains unclear. Circadian variation in hypertension, ${ }^{1}$ sudden death, ${ }^{23}$ ventricular tachyarrhythmias, ${ }^{4}$ myocardial infarction, unstable angina, ${ }^{5}$ acute cerebrovascular disease, stroke, ${ }^{6}$ subarachnoid haemorrhage, ${ }^{7}$ and ruptured aortic aneurysm ${ }^{8}$ seem to follow a similar overall pattern, with fewer events occurring in the night, followed by a sudden rise in the morning that peaks around late morning or early afternoon. In some of these studies, however, additional peaks have been reported in the late afternoon and early evening.

Cardiac arrest may have either a cardiac or a non-cardiac aetiology and may present with a variety of arrhythmias, including ventricular tachycardia, ventricular fibrillation, asystole, and electromechanical dissociation. Where prompt basic life support is available in the community, survival chances are greatest. ${ }^{9-11}$ With the exception of a few places in the USA, ${ }^{12}$ survival rates for those who reach hospital alive have been disappointing low. ${ }^{13-15} \mathrm{We}$ wondered whether there was any evidence of circadian variation in cardiac arrest occurring in our health district. Knowledge of this might help us develop strategies aimed at improving the appalling chances of survival from out of hospital cardiac arrest.

\section{Methods}

We conducted a retrospective study of all incidents of cardiac arrest in adults (defined as over 18 years of age) attended by the Nottinghamshire ambulance service from January 1991 to December 1994. Only witnessed events, where the patient was either observed or heard to collapse, were included. Unwitnessed cases were excluded because of the uncertainty of the timing of arrest.

Data were collated from the Nottinghamshire ambulance patient report forms, records of the ambulance dispatch and control unit, and all Nottinghamshire accident and emergency departments, coronary care units, and intensive care units. The presenting rhythm for each episode of cardiac arrest was obtained from the print out of the defibrillator unit; the patient report form was reviewed where the presenting rhythm was not recorded but an attempt at resuscitation was made. The coroners' records and inpatient case notes were also examined to identify all those sustaining a cardiac arrest from a "cardiac" cause (International classification of diseases, ninth revision (ICD-9), codes 390 to 414 and 420 to 429 ), usually determined from a necropsy examination but otherwise from death certificate records. Deaths attributed to a non-cardiac cause included drug overdose, suicide, drowning, hypoxia, exsanguination, cerebrovascular accident, subarachnoid haemorrhage, trauma, 


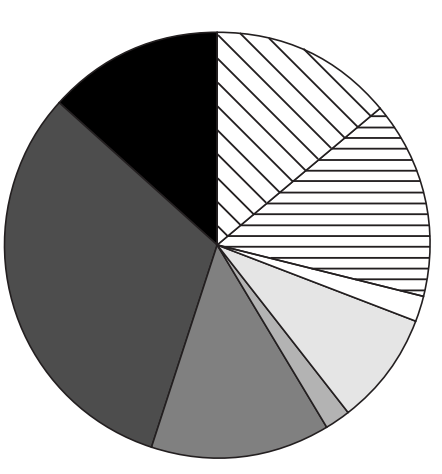

Figure 1 Witnessed arrests of non-cardiac aetiology in the community.

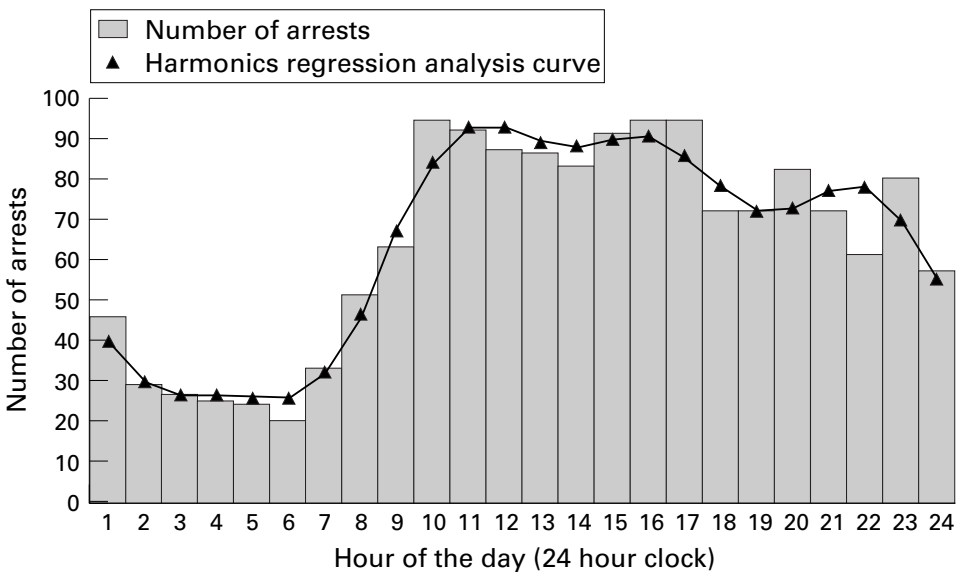

Figure 2 Circadian variation of all witnessed cardiac arrects in Nottinghamshire.

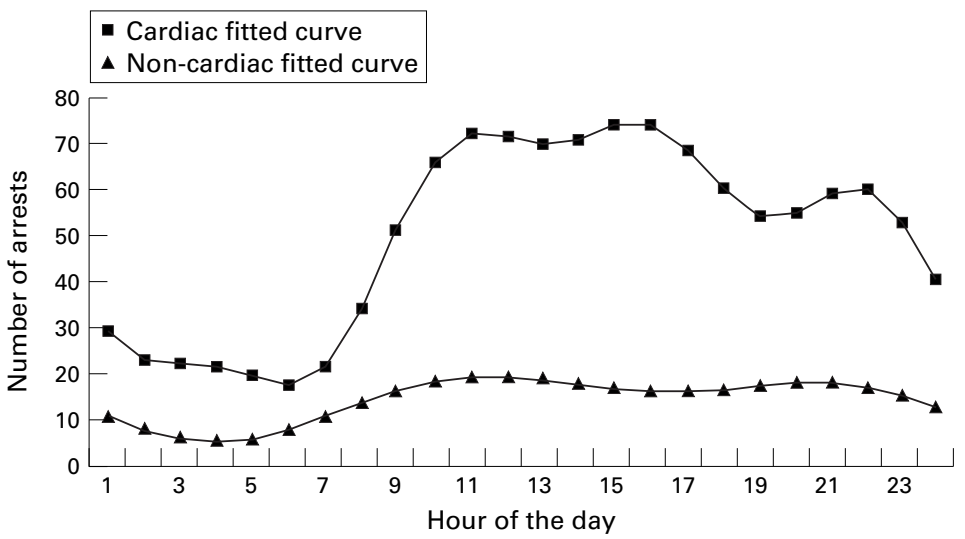

Figure 3 Harmonic regression analysis of cardiac and non-cardiac cases of out of hospital cardiac arrest.

ruptured aortic aneurysm, and pulmonary thromboembolism.

STATISTICAL METHODS

Two techniques were used to establish circadian variation over a 24 hour period from midnight to midnight. It was first necessary to establish whether any circadian variation existed. All cardiac arrest events were recorded against a time scale. The frequency-time curve was scrutinised using spectral analysis, ${ }^{16}$ a technique that describes the data in cosinusoidal terms and tests for the presence of higher frequency components. Harmonic regression analysis $^{17}$ was then used to determine the number of significant cosinusoidal compo-

nents needed to adequately fit the data. The cosine wave variation over a 24 hour period was measured by the shift in nadir from 12 am (midnight), known as the phase, and by the maximum displacement during one cycle, defined as the amplitude. The degree of phase shift and the difference in amplitude from a flat line (representing no circadian variation) determine the significance of the component. We fitted models of the form:

$$
\mathrm{x}_{\mathrm{t}}=\mu_{\mathrm{t}}+\mathrm{R} \cos (2 \pi \mathrm{t} / \mathrm{P}+\phi)+\varepsilon_{\mathrm{t}},
$$

where $\mu_{t}$ is an added constant, $R$ is the amplitude of the cosine wave, $\mathrm{P}$ is the period effect (for example, $24 \mathrm{~h}, 12 \mathrm{~h}, 8 \mathrm{~h}, 6 \mathrm{~h}$ ), $\phi$ is the phase shift, and $\varepsilon_{\mathrm{t}}$ is the residual (the value needed to make the equality exact). A stepwise regression analysis was used to determine whether each cosinusoidal component was significantly different from zero.

The $\chi^{2}$ test was used to examine discrete variables in a tabulated time series of six 4 hourly intervals to determine whether there was any variation within a group or between groups. The Kruskal-Wallis test was used to make comparisons within a group of continuous variables in a tabulated time series of six 4 hourly intervals. A probability value of $\mathrm{p}<0.05$ was considered significant in all models. The S-Plus statistical package ${ }^{18}$ was used for all analyses.

\section{Results}

Nottinghamshire ambulance service has 12 ambulance stations that serve a population of one million. Each ambulance station normally provides one accident and emergency vehicle with a crew of two, usually a paramedic and a medical technician, around the clock. Both are trained to defibrillate, although a paramedic has completed additional training and skills. The shift duty for the crew of this vehicle is from 0600 to 1400,1400 to 2200 , and 2200 to 0600 hours. Most ambulance stations provide a second accident and emergency vehicle that is operational from 0800 to 1600 hours. A few larger ambulance stations serving urban city areas provide a third vehicle operating between 1000 and 1800 hours. In exceptional circumstances, a fourth vehicle can be mobilised.

STUDY POPULATION

From January 1991 to December 1994, the Nottinghamshire ambulance service attended 2362 out of hospital cardiac arrest cases; we excluded 748 cases, as a bystander did not witness the event. The mean (SD) age of this group was $63.2(18.9), 502(67.1 \%)$ were male, 246 (32.9\%) were female, and 599 $(80.1 \%)$ arrested at home. A further 79 had incomplete records; of these, only seven were admitted to a hospital ward and all died while in hospital. The remaining 1535 cardiac arrest events form the basis of this study.

The mean (SD) age of these 1535 cases was $65.6(14.5)$ years, with $917(59.7 \%)$ of patients being aged less than 70 years; $1126(73.4 \%)$ were male, 409 (26.6\%) were female, and 1046 $(68.1 \%)$ arrested at home. 


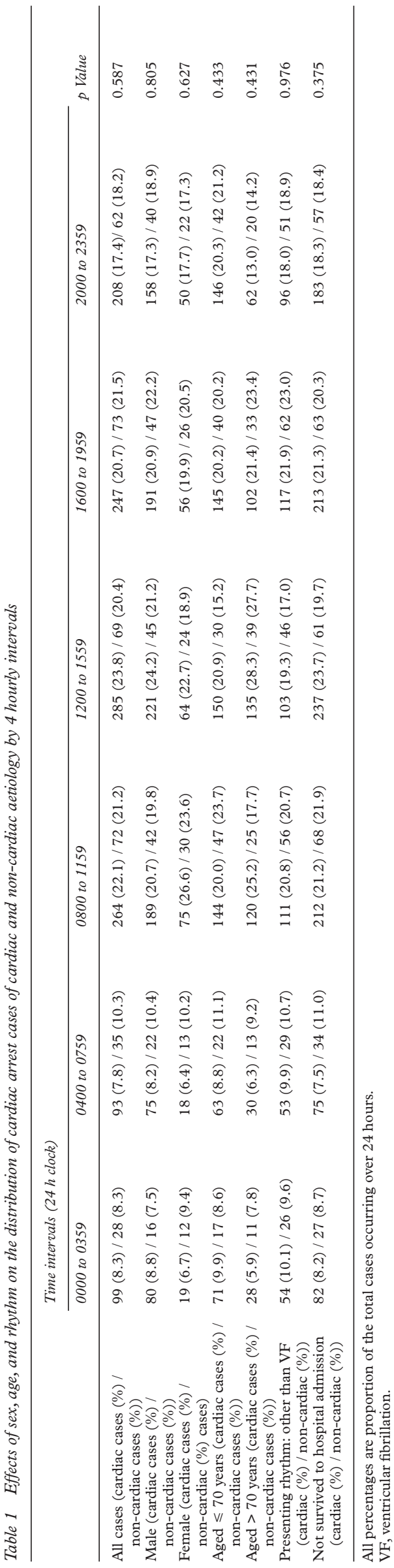

AETIOLOGY OF THE CARDIAC ARREST

Resuscitation was attempted by the ambulance crew in 1440 cardiac arrests (93.8\%). In the remaining 95 cases $(6.2 \%)$, death was attributed to a cardiac cause in $54(3.5 \%) ; 43$ (79.6\%) after necropsy.

In 1142 cases $(74.4 \%)$ where the ambulance crew attempted resuscitation, the arrest was considered to have a cardiac aetiology, falling to $827(72.4 \%)$ after necropsy. The distribution of 339 arrests of non-cardiac aetiology (234 (69\%) after necropsy), including those where there was no resuscitation attempt by the ambulance crew, is shown in fig 1 .

CIRCADIAN VARIATION IN CARDIAC ARREST FROM ALL CAUSES

Figure 2 shows the number of witnessed arrests from all causes in the community over a 24 hour period and the circadian variation: $24 \mathrm{~h}$, $12 \mathrm{~h}$, and $6 \mathrm{~h}$ circadian effects were observed $(\mathrm{p}<0.001)$. The number of witnessed arrests in the community was lowest between midnight and 0600; there was a sharp increase in the number of arrests occurring after this time, with peaks observed at approximately mid-day, 1600 , and 2200 hours $\left(R^{2}=94.3 \%, \quad \mathrm{~F}\right.$ value $=46.5, \mathrm{p}<0.001)$.

CIRCADIAN VARIATION OF CARDIAC ARREST OF CARDIAC AND NON-CARDIAC AETIOLOGY

Figure 3 compares the circadian variation in cardiac arrest of cardiac and non-cardiac aetiology. The fitted curve for cardiac cases shows peaks occurring at 1100, 1600, and 2200 hours. These are similar to the distribution of cardiac arrest from all causes, probably reflecting the number of cases of cardiac aetiology. Even so, a greater number of cardiac cases occurred later in the day at 1600 rather than at 1100 hours $\left(R^{2}=94.0 \%, \mathrm{~F}=44.5\right.$, $\mathrm{p}<0.001)$.

There were relatively fewer arrests from non-cardiac causes, which may account for the smaller degree of variation. Even so, there were fewer events between midnight and 0600 hours, after which the number of events increased during the day. There were minor peaks observed at 1200 and 2100 hours $\left(R^{2}=66.0 \%, \mathrm{~F}=9.2, \mathrm{p}<0.001\right)$ but the peak at 1600 hours observed in cardiac cases was not seen in non-cardiac cases.

The 24 hour distribution of cardiac and non-cardiac cases of cardiac arrest was divided into six 4 hourly intervals (table 1) and no difference was found between the distributions of the two groups.

EFFECT OF AGE AND SEX

Age and sex did not appear to have any impact on the distribution of cardiac and non-cardiac cases (table 1).

PRESENTING RHYTHM AND OUTCOME

Six hundred and forty three patients (41.9\%) were in ventricular fibrillation when the ambulance crew arrived. One hundred and sixty eight $(10.9 \%)$ died at home and so were not transported to hospital, while 767 (50.0\%) were taken by ambulance to an accident and 


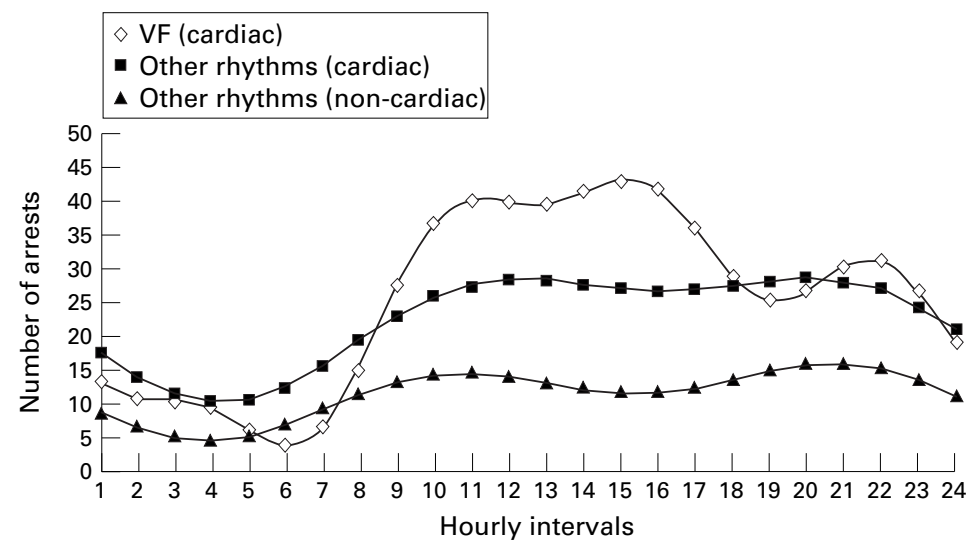

Figure 4 Harmonic regression analysis of presenting rhythm of arrest in cardiac and non-cardiac cases.

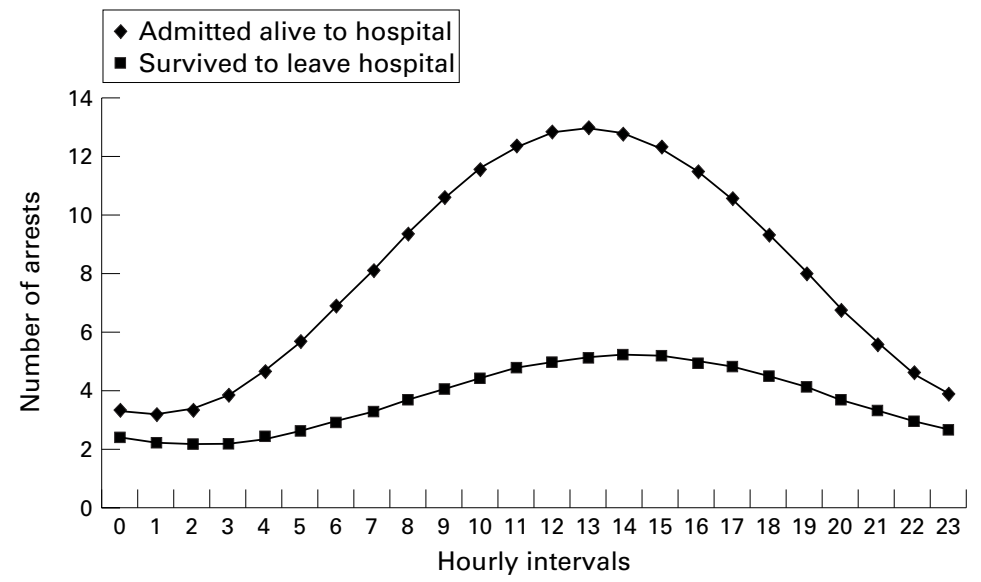

Figure 5 Harmonic regression analysis of survivors from out of hospital cardiac arrests of cardiac aetiology.

emergency (A\&E) department but were certified dead on arrival; $377(24.6 \%)$ were alive on arrival in A\&E but died there shortly afterwards. The remaining $194(12.6 \%)$ were admitted to hospital; of these only 88 patients $(5.7 \%)$ survived to be discharged alive from hospital.

DISCHARGED ALIVE FROM HOSPITAL

In $50.6 \%$ of those whose arrest was of cardiac aetiology (605 of 1196), the presenting rhythm was ventricular fibrillation, and 80 of these survived; in $23.4 \%(\mathrm{n}=280)$, asystole was recorded and two survived to leave hospital alive; $9.0 \%(n=108)$ were in electromechanical dissociation, of whom three survived to leave hos- pital alive; $5.1 \%(n=61)$ had pulseless idioventricular rhythm and $12.2 \%(\mathrm{n}=85)$ had fine ventricular fibrillation, none of whom survived. The rhythm was not known in $4.8 \%(\mathrm{n}=57)$ and three of these cases survived.

Of the non-cardiac cases, the presenting rhythm of arrest in $11.2 \%$ was ventricular fibrillation (38 of 339); other (non-VF) rhythms were recorded in $79.6 \%(n=270)$ and the rhythm was not known in $9.1 \%$ $(\mathrm{n}=31)$. Only one of the non-cardiac casespresenting with asystole-survived to leave hospital alive.

CIRCADIAN VARIATION AND PRESENTING RHYTHM For those presenting with ventricular fibrillation of cardiac aetiology, peaks in circadian variation occurred around 1100, 1500, and 2200 hours $\left(R^{2}=93.6 \%, \quad \mathrm{~F}=41.2\right.$, $\mathrm{p}<0.001$ ), with the highest peak being at 1500 hours (fig 4).

Harmonic analysis was not performed for non-cardiac cases presenting with ventricular fibrillation because the number of cases was small. The circadian variation for rhythms other than ventricular fibrillation was identical in both cardiac $\left(R^{2}=69.6 \%, \mathrm{~F}=10.8, \mathrm{p}<0.001\right)$ and non-cardiac cases $\left(R^{2}=64.2 \%, \quad \mathrm{~F}=8.5\right.$, $\mathrm{p}<0.001$ ), with peaks occurring around 1130 to 1230 hours and around 2030 hours. This was confirmed when their distribution was compared by six 4 hourly intervals over a 24 hour period $(\mathrm{p}=0.967)$ (table 1$)$.

For cases of cardiac aetiology, we compared the distribution of ventricular fibrillation cases with other rhythms by dividing the 24 hour period into six 4 hourly intervals, as shown in table 2, and a significant difference was found between the two groups $(\mathrm{p}=0.005)$. There was an expectedly low number of incidents of bystander resuscitation after midnight, which subsequently increased and reached a plateau after 0800 hours. The ambulance crew response times appear to make a small but significant difference, with slightly slower response times from midnight to 0359 hours and from 1600 to 1959 hours. The slower response times might be because there were fewer vehicles during these periods. The combination of infrequent bystander resuscitation and slower ambulance response times could account for the troughs seen in the circadian

Table 2 The variation of cardiac cases over 24 hours of the ambulance crews response time intervals, bystander cardiopulmonary resuscitation, presenting rhythm, and non-survivors to hospital

\begin{tabular}{|c|c|c|c|c|c|c|c|}
\hline & \multicolumn{6}{|c|}{ Time intervals ( $24 \mathrm{~h}$ clock) } & \multirow[b]{2}{*}{$p$ Value } \\
\hline & 0000 to 0359 & 0400 to 0759 & 0800 to 1159 & 1200 to 1559 & 1600 to 1959 & 2000 to 2359 & \\
\hline $\begin{array}{l}\text { Response times by ambulance crew, median } \\
\text { time (min) (interquartile range) }\end{array}$ & 7 (5 to 9$)$ & $6(5$ to 8$)$ & $6(4$ to 8$)$ & $6(4$ to 9$)$ & 7 (5 to 9$)$ & $6(4$ to 9$)$ & 0.022 \\
\hline \multicolumn{8}{|l|}{ Presenting rhythm } \\
\hline VF (\%) & $44(44.4)$ & $36(38.7)$ & $141(53.4)$ & $161(56.5)$ & $118(47.8)$ & $105(50.5)$ & 0.030 \\
\hline Non-VF (\%) & $54(54.5)$ & $53(57.0)$ & $111(42.0)$ & $103(36.1)$ & $117(47.4)$ & $96(46.2)$ & $0.001\left(0.005^{\star}\right)$ \\
\hline Unknown (\%) & 0 & $4(4.3)$ & $12(4.5)$ & $21(7.4)$ & $12(4.9)$ & $7(3.4)$ & NA \\
\hline Bystander CPR (\%) & $26(26.3)$ & $12(12.9)$ & $97(36.7)$ & $111(38.9)$ & $85(34.4)$ & $81(38.9)$ & $\begin{array}{l}<0.001 \\
\left(0.306^{\star}\right)\end{array}$ \\
\hline Survival to hospital admission (\%) & $17(17.2)$ & $18(19.4)$ & $52(19.7)$ & $48(16.8)$ & $34(13.8)$ & $25(12.0)$ & $0.223\left(0.318^{\star}\right)$ \\
\hline Survival to hospital discharge (\%) & $10(10.1)$ & $8(8.6)$ & $21(8.0)$ & $18(6.3)$ & $16(6.5)$ & $15(7.2)$ & $0.823\left(0.542^{\star}\right)$ \\
\hline
\end{tabular}

All percentages are proportion of total cases occurring within each 4 hour period. ${ }^{\star}$ Compared with distribution of VF rhythm of arrest cases. CPR, cardiopulmonary resuscitation; NA, not assessed; VF, ventricular fibrillation. 
variation of ventricular fibrillation between midnight and 0800 hours and around 1900 hours.

Survival to both hospital admission $\left(R^{2}=62.8 \%, \mathrm{~F}=17.8, \mathrm{p}<0.001\right)$ and to hospital discharge $\left(R^{2}=25.4 \%, \mathrm{~F}=25.2\right.$, $\mathrm{p}=0.046)$ for cases of cardiac aetiology were also found to show a circadian variation, with a single event peak occurring around 1300 hours (fig 5). However, the fitted harmonic curves had low $R^{2}$ value owing to the small number of events.

The distribution of those who were alive on reaching hospital and were subsequently discharged was examined concurrently with cases presenting with ventricular fibrillation rhythm (table 2); no difference between the circadian variation of the two groups was observed.

\section{Discussion}

The likelihood of a "sudden death" episode occurring and being witnessed is not constant throughout the day. We observed that there were three major time periods when a cardiac arrest was most likely to occur-an early peak in the morning around 1100 hours, a late peak in the evening around 2200 hours, and, for those whose arrest was from a cardiac disease, a third time period - around 1600 hours - also seemed to be critical.

There does not seem to be any consistent pattern to circadian variation in published reports. In Seattle ${ }^{19}$ and Berlin, ${ }^{20}$ the most important times for a cardiac arrest seemed to be around 1000 and 1800 hours. Ventricular fibrillation was most frequent around 2000 hours in the series by Peckova and colleagues, while Arntz and associates found that ventricular fibrillation occurred most often around 1000 hours, very similar to our own findings. Differences such as these probably arise for several reasons: methodological difficulties, not least in defining what is meant by "sudden death"; timing the onset of the acute event with any degree of accuracy; reliance on accurate data collection of ambulance staff rather than direct contact which increases the proportion of arrests designated as "witnessed ventricular fibrillation" ${ }^{21}$; accounting for events that are unwitnessed; excluding those who survive the acute event; and failing to establish from death certificate data or necropsy reports the underlying aetiology. We tried to address these potential problems by clearly defining sudden death, recording the response time to a call for out of hospital resuscitation by our ambulance service, which is continually monitored, comparing witnessed arrest of different aetiology to reduce the bias from unwitnessed events late at night, auditing the outcome of all patients in the study, and obtaining information on the cause of death, using necropsy data where available.

We are confident that our omission of unwitnessed events had little impact on our findings because the significance and pattern of the circadian variation remained unchanged even when all unwitnessed events are assumed to have occurred during late at night and early in the morning, ${ }^{23}$ and there is a low frequency $(12.3 \%)$ of sudden cardiac death during sleep. ${ }^{2}$

We did find that the periods when ventricular fibrillation were most likely to occur coincided with periods of faster response time by the ambulance crews, leading to early cardiac monitoring, as well as periods in which bystander resuscitation was more likely to be initiated, maintaining cardiac output until the ambulance crew arrived. ${ }^{922} 23$ These factors potentially affected the circadian variation of arrhythmia, particularly ventricular fibrillation, and could also account for the diverse findings reported so far.

We are unaware of any previous study that has examined circadian variation of out of hospital arrest of non-cardiac aetiology. This group of patients is not homogeneous-one third had some vascular disorder such as ruptured or dissected aortic aneurysm, subarachnoid haemorrhage, and cerebrovascular accidents. Such heterogeneity might be expected to lead to events being randomly distributed throughout the day and night, though others have reported circadian variation for some of the conditions in our series. $^{8724}$

We were surprised to find that, with the exception of ventricular fibrillation, the circadian variation of the arrest rhythm in both cardiac and non-cardiac groups appeared to be identical. The triggers for a cardiac arrest in both groups are likely to be similar when the arrhythmia is something other than ventricular fibrillation, irrespective of the aetiology of arrest. Vigorous physical activity ${ }^{25}$ is one potential trigger, but this is disputed by others, ${ }^{26}$ including studies based on pathology $y^{27-29}$ and Holter monitoring. ${ }^{30}$ Changes in blood pressure, ${ }^{31}$ vascular tone, ${ }^{32}$ platelet activation, ${ }^{33}$ and hormonal concentrations of adrenaline (epinephrine), ${ }^{33}$ noradrenaline (norepinephrine), ${ }^{33}$ renin, ${ }^{34}$ and cortisol ${ }^{35}$ are examples of some physiological processes caused by a triggering activity.

The chances of a Nottingham resident surviving an out of hospital cardiac arrest are generally very poor. ${ }^{15}$ Can we use knowledge about the circadian variation of out of hospital cardiac arrest to improve survival rates? The chances of survival are generally dismal when the presenting rhythm is asystole or electromechanical dissociation. ${ }^{36-39}$ This presumably reflects varying but catastrophic aetiology, so it is probably futile to expect to influence the outcome in this group. ${ }^{40}$ However, it might be more rewarding to identify trigger factors for this type of rhythm of arrest from future studies on circadian variation and to attempt modification of these factors as part of preventative measures.

The chances of surviving an out of hospital cardiac arrest are best when the arrhythmia is ventricular fibrillation. It is interesting that the circadian variation we observed among those who survive an out of hospital cardiac arrest matches the circadian pattern of ventricular fibrillation in Seattle, where the chances of surviving and being discharged alive are about 
$12.4 \%,{ }^{19}$ although survival in Nottingham was only half that.

Our lower survival rate is most likely to reflect two factors. First, in very few cases (about one third of all those whose arrest is witnessed) is resuscitation started before the arrival of the ambulance crew. Providing training in basic life support for a large proportion of the community is one approach, ${ }^{41}$ but it may be more cost-effective to focus attention on those with at-risk partners. Second, as we have previously reported, ${ }^{15}$ the response times of our ambulances were probably too long, at six minutes (median), to influence the outcome. Response times in Rochester ${ }^{42}$ and Seattle, ${ }^{43}$ of 2.7 minutes and 3.6 minutes, have produced far superior survival rates. Knowing when cardiac arrest occurrence is most likely could facilitate the deployment of ambulance crew or suitably trained health professionals at peak times (which for ventricular fibrillation in Nottingham is from 1000 to 2200 hours). We might expect to improve the survival chances for 196 cases a year $(66 \%$ of all ventricular fibrillation cases) presenting in ventricular fibrillation.

Strategies to improve survival chances following cardiac arrest from ventricular fibrillation continue to present a challenge. There are several alternatives. Effective preventive measures could be developed if we had a better understanding of the pathophysiological triggers to cardiac arrhythmia and an explanation for its predilection for certain times of the day. There are proposals to provide defibrillators in the community but these will benefit only those whose collapse occurs in a public place-about one quarter of our series - and in the presence of a reliably trained individual. ${ }^{15}$ When suitably trained and equipped ambulance personnel are at hand during an arrest, survival chances are greatly improved to about 40-57\%. ${ }^{13} 153944$ While many episodes of ventricular fibrillation will continue to occur in the absence of trained personnel, ambulance controllers might benefit their local population by incorporating information on circadian variation into their computer programs advising on ambulance deployment.

1 Millar B, Craig MW, Bishop CN, et al. Circadian variation of blood-pressure. Lancet 1978;i:795-7.

2 Muller JE, Ludmer PL, Willich SN, et al. Circadian variation in the frequency of sudden cardiac death. Circulation 1987;75:131-8.

3 Willich SN, Levy D, Rocco MB, et al. Circadian variation in the incidence of sudden cardiac death in the Framingham heart study population. Am $\mathcal{f}$ Cardiol 1987;60:801-6.

4 Lampert R, Rosenfeld L, Batsford W, et al. Circadian variation of sustained ventricular tachycardia in patients with tion of sustained ventricular tachycardia in patients with coronary artery disease and implantab
defibrillators. Circulation 1994;90:241-7.

5 Cannon $\mathrm{CP}, \mathrm{McC}$ abe $\mathrm{CH}$, Stone PH, et al. Circadian variation in the onset of unstable angina and non-Q-wave acute myocardial infarction (the TIMI III registry and TIM IIIB). Am f Cardiol 1997;79:253-8.

6 Marler JR, Price TR, Clark GL, et al. Morning increase in onset of ischemic stroke. Stroke 1989;20:473-6.

7 Gallerani M, Portaluppi F, Maida G. Circadian and circannual rhythmicity in the occurrence of subarachnoid haemorrhage. Stroke 1996;27:1793-7.

8 Manfredini R, Portaluppi F, Zamboni P. Circadian variation in spontaneous rupture of abdominal aorta. Lancet in spont353:643-4.

9 Herlitz J, Ekstrom L, Wennerblom B, et al. Effect of bystander initiated cardiopulmonary resuscitation on bystander initiated cardiopulmonary resuscitation on
ventricular fibrillation and survival after witnessed cardiac ventricular fibrillation and survival after witnessed carc
10 Swor R, Jackson R, Cynar M, et al. Bystander CPR, ventricular fibrillation, and survival in witnessed, unmonitored out-of-hospital cardiac arrest. Ann Emerg Med 1995; 25:780-4.

11 Eisenberg MS, Bergner L, Hallstrom A. Cardiac resuscitation in the community. Importance of rapid provision and implications for program planning. $尹 A M A 1979 ; 241: 1905-7$.

12 Cobb LA, Weaver WD, Fahrenbruch CE, et al. Communitybased interventions for sudden cardiac death. Impact, limitations, and changes. Circulation 1992;85(suppl I):I98-102.

13 Norris R. Fatality outside hospital from acute coronary events in three British health districts, 1994-5. BMF 1998; 316:1065-70.

14 Eisenberg M, Horwood B, Cummins RO, et al. Cardiac arrest and resuscitation: a tale of 29 cities. Ann Emerg Med 1990;19:179-86.

15 Soo LH, Gray D, Young T, et al. Resuscitation from out-ofhospital cardiac arrest: is survival dependent on who is available at the scene? Heart 1999;81:47-52.

16 Janacek G, Swift L. Time series: forecasting, simulation, applications. Ellis Horwood Ltd, 1993.

17 Bloomfield P. Fourier analysis of time series: an introduction. New York: John Wiley and sons, 1976.

$18 \mathrm{~S}$-plus guide to statistical and mathematical analysis [program]. Version 3.2. Seattle: StatSci, 1993.

19 Peckova M, Fahrenbruch CE, Cobb LA, et al. Circadian variations in the occurrence of cardiac arrests: initial and repeat episodes. Circulation 1998;98:31-9.

20 Arntz HR, Willich SN, Oeff M, et al. Circadian variation of sudden cardiac death reflects age-related variability in ventricular fibrillation. Circulation 1993;88:2284-9.

21 Gallagher EJ, Lombardi G, Gennis P, et al. Methodologydependent variation in documentation of outcome predictors in out-of-hospital cardiac arrest. Acad Emerg Med 1994;1:423-9.

22 Ritter G, Wolfe RA, Goldstein S, et al. The effect of bystander CPR on survival of out-of-hospital cardiac arrest victims. Am Heart 7 1985;110:932-7.

23 Cummins RO, Eisenberg MS, Hallstrom AP, et al. Survival of out-of-hospital cardiac arrest with early initiation of cardiopulmonary resuscitation. Am f Emerg Med 1985;3:114-19.

24 Argentino C, Toni D, Rasura M, et al. Circadian variation in the frequency of ischemic stroke. Stroke 1990;21:387-9.

25 Siscovick DS, Weiss NS, Fletcher RH, et al. The incidence of primary cardiac arrest during vigorous exercise. $N$ Engl F Med 1984;311:874-7.

26 de Vreede-Swagemakers JJ, Gorgels AP, Dubois-Arbouw WI, et al. Out-of-hospital cardiac arrest in the 1990's: a population-based study in the Maastricht area on incidence, characteristics and survival. 7 Am Coll Cardiol 1997; 30:1500-5.

27 el Fawal MA, Berg GA, Wheatley DJ, et al. Sudden coronary death in Glasgow: nature and frequency of acute coronary leath in Glasgow: nature and frequenc.

28 Liberthson RR, Nagel EL, Hirschman JC, et al. Pathophysiologic observations in prehospital ventricular fibrillation and sudden cardiac death. Circulation 1974;49:790-8.

29 Myers A, Dewar HA. Circumstances attending 100 sudden deaths from coronary artery disease with coroner's necropsies. Br Heart $\mathcal{f}$ 1975;37:1133-43.

30 Bayes de Luna A, Coumel P, Leclercq JF. Ambulatory sudden cardiac death: mechanisms of production of fatal arrhythmia on the basis of data from 157 cases. Am Heart 7 1989;117:151-9.

31 Kleinpeter G, Schatzer R, Bock F. Is blood pressure really a trigger for the circadian rhythm of subarachnoid hemorrhage? Stroke 1995;26:1805-10.

32 Panza JA, Epstein SE, Quyyumi AA. Circadian variation in vascular tone and its relation to alpha-sympathetic vascular tone and its relation to alpha-sympathetic
vasoconstrictor activity [see comments]. $N$ Engl $f$ Med vasoconstrictor activi

33 Tofler GH, Brezinski D, Schafer AI, et al. Concurrent morning increase in platelet aggregability and the risk of myocardial infarction and sudden cardiac death. $N$ Engl $\mathcal{F}$ Med 1987;316:1514-18.

34 Gordon R, Wolfe L, Island D, et al. A diurnal rhythm of plasma renin activity in man. F Clin Invest 1966;45:158792.

35 Weitzman E, Fukushima D, Nogeire C, et al. Twenty-four hour pattern of the episodic secretion of cortisol in normal subjects. F Clin Endocrinol Metab 1971;33:14-22.

36 Weston CF, Stephens MR. An audit of cardiac arrest management by extended trained ambulance crew. Resuscitation 1992;23:207-16.

37 van der Hoeven JG, Waanders $\mathrm{H}$, Compier EA, et al. Prolonged resuscitation efforts for cardiac arrest patients who cannot be resuscitated at the scene: who is likely to who cannot be resuscitated at the scene: who
benefit? Ann Emerg Med 1993;22:1659-63.

38 Herlitz J, Ekstrom L, Wennerblom B, et al. Predictors of early and late survival after out-of-hospital cardiac arrest in which asystole was the first recorded arrhythmia on scene. Resuscitation 1994;28:27-36.

39 Wright D, Bannister J, Ryder M, et al. Resuscitation of patients with cardiac arrest by ambulance staff with extended training in West Yorkshire. BMF 1990;301:600-2.

40 Kurkciyan I, Meron G, Behringer W, et al. Accuracy and impact of presumed cause in patients with cardiac arrest. Circulation 1998;98:766-71.

41 Cobb LA, Weaver WD, Hallstrom AP, et al. Cardiac resuscitation in the community. The Seattle experience. Cardiologia 1990;35(suppl 1):85-90.

42 White RD, Vukov LF, Bugliosi TF. Early defibrillation by police: initial experience with measurement of critical time 
intervals and patient outcome. Ann Emerg Med 1994;23. 1009-13

, Hill D, Fahrenbruch CE, et al. Use of the au matic external defibrillator in the management of out-ofhospital cardiac arrest. N Engl f Med 1988;319:661-6.
44 Sedgwick ML, Dalziel K, Watson J, et al. Performance of an established system of first responder out-of-hospital defibrillation. The results of the second year of the Heartstart Scotland Project in the "Utstein Style". Resuscitation 1993;26:75-88

\section{IMAGES IN CARDIOLOGY}

\section{Colour coded blood flow imaging in intravascular ultrasound}

A 42 year old man was admitted to our hospital with sudden chest pain. The exercise ECG showed inferior ST segment depression suggesting ischaemia. Coronary angiography revealed a normal left coronary artery and severe proximal stenosis of the right coronary artery. The patient underwent direct percutaneous transluminal coronary angioplasty with coronary stent-graft implantation. The stent-graft is a combination of a metal stent with a membrane of polytetrafluorethylene. Angiography suggested good stent apposition without residual stenosis. With standard intravascular ultrasound (IVUS) full stent expansion was assessed (A, large arrow: stent-graft; small arrow: lumen), revealing a weak signal distal of the stent caused by partial absorption of the ultrasound signal from the specific stent graft material. In contrast to angiography and standard IVUS, colour coded blood flow imaging revealed incomplete apposition in the proximal entrance of the stent graft in more than $50 \%$ of the circumference documented by blood flow (red) in the two dimensional image (B, arrows) plane as well as in the sagittal reconstruction of the vessel (C, arrows).

Colour coded blood flow imaging is a recently introduced and commercially available technique encoding the rate of change of the backscatter echo of the blood cells into colour. Since the ultrasound beam is identical to the one used in standard IVUS, the colour information is displayed simultaneously with the standard IVUS information. Flow between the stent and the vessel wall was documented only with colour coding, representing incomplete attachment of the stent to the vessel wall (B and C, arrows). Colour coded blood flow imaging is a useful adjunct to standard greyscale IVUS in specific lesions.

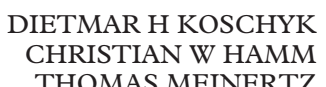

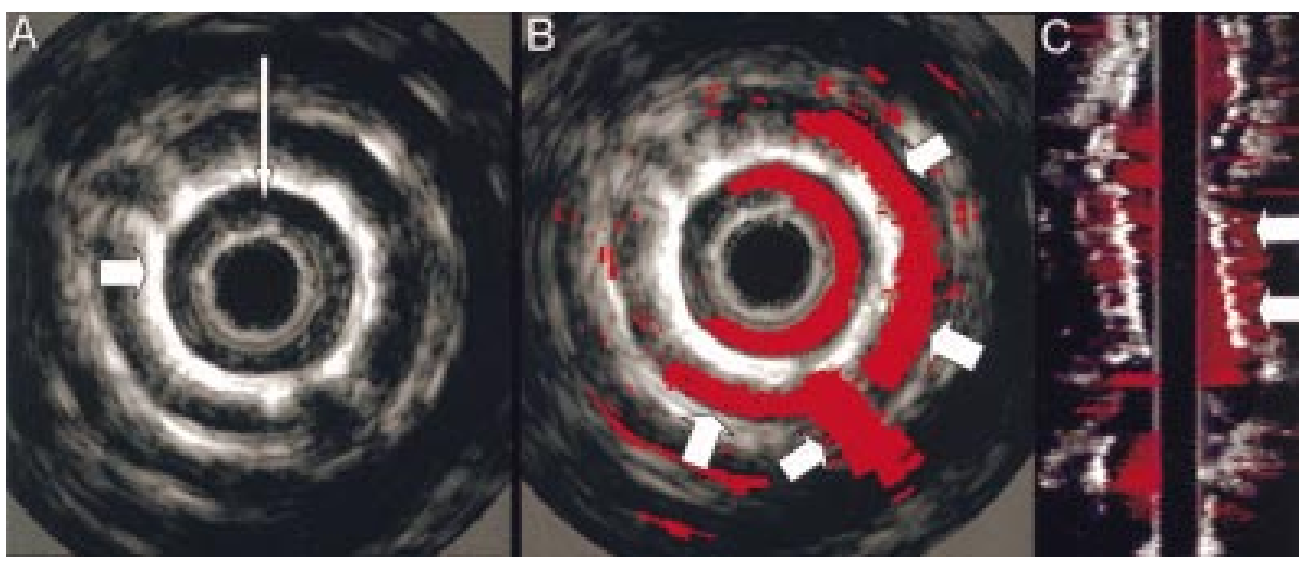

